\title{
4
}

\section{Diagnosing Dementia}

\author{
Epidemiological and Clinical Data \\ as Cultural Text
}

\author{
JANICE E. GRAHAM
}

\begin{abstract}
What meanings are hidden in the plaques and tangles of an atrophying brain, in the artifacts of diagnostic clinical history, in the bioinformatic matrices of an epidemiological database? Or in the lived experiences of a still-active mind trying to express a voice, to perform an action, but unable to find the means to do so? How do seemingly disparate bits and pieces of pathology, clinical history, social relationships, and specialist training come together? How do these fractured components form interpretable constellations that help us better understand the science; the sufferers; the relationships between dementia, data, and the diagnostic process?
\end{abstract}

In this chapter, I explore the concepts used by clinicians in the practice of differentially diagnosing dementia. Based upon standard clinical texts, and from the many "cases" seen in the past and discussed among colleagues, a medical diagnosis is an interpretation that a clinician constructs by piecing together symptoms provided from the narrative of a suffering person during a clinical interview and signs from that person's physical examination and tests. The frequency of occurrence of these symptoms and signs form characteristic patterns that match those of other, similar cases or stand out as somewhat different. The patterns direct the physician along one or another diagnostic path. Researchers collect these diagnostic symptoms and signs with other information and inscribe them in clinical, epidemiological, and health-service databases. These facts inform and direct health-care practice, policy, and planning. Over time, the data also serve to transform the standardized diagnostic criteria.

What is often unrecognized is that the culturally conditioned practices of the people and institutions that construct the data are also, often unknowingly, incorporated into the body of these databases. The instruments that dictate 
facts, the assemblages of local and expert knowledge used to guide choice, and the decisions that are arrived at and appear in these electronic repositories as separate yet interrelated elements allow a researcher to explore similarities and redundancies, as well as incoherences and incommensurabilities. This chapter shows the extent to which physicians see through the lenses of their clinical specialties in the execution of standardized criteria, how dementia is actualized in diagnostic practice and then written into data, and how these data may disclose more than the raw information instantiated within.

The methodology described here includes a comparative analysis of the established medical criteria with data from nearly three thousand extensive clinical assessments of elderly people that were collected as part of a nationalpopulation representative epidemiological survey of dementia. The bilingual Canadian Study of Health and Aging ([CSHA] I994, 200O; Graham et al. I996a; Tuokko 2003) involved interviewing IO,263 Canadians age sixty-five and over, from British Columbia to Newfoundland. Most lived in the community; I2 percent resided in institutional care facilities. All participants received the Modified Mini Mental State (3MS) screening test for cognitive impairment (Teng and Chui 1987). From the community, all those who tested positive for cognitive impairment and a sample of those testing negative were followed up with a more extensive neuropsychological assessment, clinical examination, and medical history $(n=1,608)$. All residents of care facilities received the clinical examination (I,255). Relatives of all study participants provided personal and family history using section $\mathrm{H}$ of the Cambridge Mental Disorders Examination (CAMDEX) (Roth et al. I988).

I worked as the clinical database manager for the CSHA between I99I and 1993. My initial job was to determine the reliability and validity of the clinical data from the eighteen study centers. Later, during doctoral and postdoctoral studies in anthropology, neuroepidemiology, and geriatric medicine, I explored the differential diagnoses of cognitive impairment and dementia in light of standardized criteria. Although the majority of dementia diagnoses were subtyped as Alzheimer's disease, I began to examine other possible paths toward subtype differentiation within the dementia syndrome. ${ }^{1}$

IN THIS CHAPTER I detail a comparative approach to understanding dementia from three separate but connected sources of information:

1. The established clinical diagnostic criteria for dementia as derived from the Diagnostic and Statistical Manual of Mental Disorders (DSM) (APA I987, 1994), the tenth revision of the International Classification of Diseases (ICD) (World Health Organization [WHO] 1989, 1993) for vascular and other dementias, and the NINCDS-ADRDA ${ }^{2}$ criteria for probable and possible Alzheimer's disease (McKhann et al. 1984). Later developments introduced 
new criteria, for example, for dementia of the Lewy body type (McKeith et al. 1992), that had not originally been targeted during the CSHA survey. I call this information the written standardized text.

2. An epidemiological database electronically compiled from raw data, cataloging symptoms and signs collected as part of a national epidemiological study by clinicians from several specialties (database text).

3. The often unknown information embedded in the database text that can show, as in the examples presented here, important relationships between signs and symptoms, and also how specialists, who represent local expert cultures within medicine, differentially operationalize standardized criteria for dementia (belief-practice text).

\section{Databases as Cultural Text}

I wish to make the claim that a database can be understood as a text in the way that Hanks (I989) defines text as a "sociocultural product and process . . . [that] can be taken (heuristically) to designate any configuration of signs that is coherently interpretable by some community of users." The text is located in the "social matrix within which the discourse is produced and understood" (9596). My position is that the database holds unique information, but importantly, as a text of the culture that produces it, it remains "subordinate to culture" (Bibeau and Corin 1994). It contains facts or ideas that are not easily disaggregated from the values and beliefs of those constructing the data.

There is considerable potential for databases to be more productively engaged as organic structures for interpreting beyond what Latour and Woolgar (I986) call "brute facts." By reconfiguring the sets of elements within a database, we can explore classifications, similarities, differences, and relations that the observers who initially collected the information and created the database may not have recognized. While new tools in informatics allow for easier navigation of archived data that await innovative findings through secondary analyses, it becomes ever more important to remain cautious of these secondary analyses, or data prospecting, since, as Dumont has told us, referring to very different materials, "all documents [do not] have the same value" (I986, I9I). In secondary analyses of existing databases, especially those that are maintained over long periods with several timepoints of data entry, the ethnographer can track and uncover how the meanings that are assigned to objects shift over time, what Appadurai (I986) has called "the social life of things." In a chapter that pays particular respect to the works of Mauss, Dumont emphasizes the ethnographer's task "to dig beneath the best native information" to the "underlying facts, which are almost unconscious because they exist only in collective tradition. But these are the real facts, the things [cf. Durkheim!] that we shall try to reach through the documents" (I986, I9I). Anthropological methods are 
adaptable to interpreting electronic fieldwork sites (databases), where "almost unconscious" facts can be found in what I call here the physician's "beliefpractice text."

Social and historical drivers, the political nature of data, are locked in and can also be constructed from these seemingly static repositories. The variables initially observed, collected, and correlated can be countered by an almost infinite array of factors that are not included. While epidemiologists struggle to assure users of the controlled nature of the databases they design, that is a very limited and essentialist representation of what is, in actuality, a stochastic world in ever changing activity. While prediction is the central pillar of science (Casti 1990), and is approached using deduction in physics and astronomy, for example, the capability to explain lessens progressively as we move into biology, economics, and other social sciences and into the humanities. However, some level of prediction is possible, even if only in a statistical sense as a probability statement with degrees of confidence. And while some interpretations may be better than others (Eco I990), it is important that the criteria used to make such determinations transparent for scrutiny.

If a strength of the morally and practically "obliged” ethnographer (Lambek I99I, 49, in theory; Maranda I994, 435, in practice) is in orchestrating multiple voices and meanings, why not extend our study sites and fieldwork to databases, where much activity is being deposited? Yet we must endeavor to create a space in these electronic mines for sociohistorical context, without which there would be no limit to the ambiguity of the symbols (the signs and symptoms) that compose meanings, which tell so much more about the cultures, situations, and individuals relating within. "Context implies that all meaning is a matter of degree, probability, multiplicity, and, from the individual's point of view, indeterminacy" (Friedrich 1986, I9). The exercise here is to consider the textuality of databases and diagnoses. It allows poetics, the diversity of voices, styles, practices, and politics, to play in harmony with science, which articulates methods to determine degrees of probability of these various interpretations.

An anthropologist's critical attention to how power resides in and transforms arrangements between individuals and groups can show how dominant ideological and social patterns are intimately related to hegemonic ideologies and practices. Empirical, systematic research methods allow us to attend to the sources, agencies, and relationships that are used to construct facts in science.

We can deconstruct the truth claims of science by showing the radical historical specificity, and so contestability, of the very layer of the onion of scientific constructions. Anthropologists underline how scientific activity is not always about uncovering "nature." It is a fierce fight to construct reality. Ethnographers slay positivistic facts and accepted ideals that create an aura of facticity (fact seeking, fact finding) in a sea of interpretations. Making biopolitics clearer, and acknowledging the ethical-political choices involved in what are 
reported as neutral positions of fact in these proliferating databases (Agamben I998; Keenan I997), remains a work in the anthropology of science and biotechnology (Bibeau, Graham, Fleising, forthcoming).

The database is not the antithesis of hermeneutics. The ambiguities present in the actual lives of people and the institutional bodies that surround them are recorded and incorporated into databases; they are fuzzy and muddled, despite their predefined categories. Coded facts do assault the hermeneutical position, but they also compel attempts to interpret and understand. People can enter databases after the fact and create (compute) new variables from the old, build new models, algorithms, and criteria that were not conceived at the time the data were written. We can dissect the old, and write new stories. Multiple interpretations can be read. Databases are imperfect objects created by experts targeting the other. Nevertheless, they offer a landscape of ethnographic riches.

\section{Dementia: Making Sense of the Diagnostic Categories}

At the 1996 Lancet conference to address "the challenge of the dementias," Raymond Tallis, an eminent British geriatrician, strongly suggested that it was time to "reboot the disk" in the nosology of dementia, to let us start anew with different models of criteria. ${ }^{3}$ While I agree, this clinical directive does, however, require some caution, for it is the structure rather than the content of our nosological "disks" that requires rethinking. It is the very content, in all its disarray, that might allow us to reinvent more dynamic "categories" that may prove to have buried within them useful connections, with the capacity to address the personal interrelationships and management of, and perhaps therapeutic approaches to, those suffering from senility and their caregivers and families. Existing data are rich resources that reveal the direction the models might take. In this chapter I make the case for an anthropologically inductive interpretive approach, which nevertheless makes use of sophisticated mathematical modeling to build upon the strength of interpretations. This approach contrasts with the deductive techniques more commonly used in epidemiology and in medicine.

The growth of interest in cognitive impairment has generated new approaches to dementia with an increased appreciation of the central importance of heterogeneity in its subdiagnosis (Graham et al. 1997, 1999). The syndromic diagnosis (that is, the definition of dementia) was revised both in DSM-IV (APA I994), and in ICD-IO (WHO I993). Dementia, using these criteria, is clinically identified as a progressive degenerative disorder characterized by "a decline from a previously higher level of functioning" and by multiple cognitive deficits that "must be sufficiently severe to cause impairment in occupational or social functioning” (APA 1994, I34). An appreciation of previously unrecognized causes of cognitive impairment, such as frontotemporal dementia (Lund and 
Manchester 1994) and dementia of the Lewy body type (McKeith et al. 1992), has coincided with substantial changes in the way in which more established causes of dementia are being redefined. Significant emerging developments in understanding vascular causes of cognitive impairment have been driven by the ability to target identifiable risk factors, which have so far eluded researchers of Alzheimer's disease (Roman et al. I993; Chui et al. I992; Rockwood et al. I994, 2000; Hachinski 1992, I994; Mitnitski et al. I997; Nyehhuis and Gorelick I998; Graham et al. I999; Jellinger and Mitter-Ferstl 2003; Erkinjuntti et al. 2004). As a result of improved understandings of the existence of these definable subgroups, Alzheimer's disease-which had the full support of a remarkable lobbying platform by the National Institute of Neurological and Communications Disorders and Stroke (NINCDS) committee within the United States National Institutes of Health (NIH) (McKhann et al. I984; Fox I989; Adelman I995)-has encountered a challenge to its former preeminent diagnostic status (Erkinjuntti et al. 1994; Blennow, Wallin, and Gottfries 1994; Emery and Oxman I994; Bowler and Hachinski 2003). The development of treatments and the role of the pharmaceutical industry in restructuring this understanding provided a market opportunity during the I990s. But that is another story (Graham 200I, 2003). ${ }^{4}$

Despite a few voices that could be heard promoting "the ubiquity of brain/ mind interactions" and warning that "problems in living necessarily influence brain state and structure” (Eisenberg I986, 503), the predominant mindscape of the medical community has been focused on a pathological/anatomical explanation for degenerating cognition and behavior. Although causes of the various subtypes of dementia cannot be determined in the absence of readily available biological markers, an assessment of the personal and medical history of the clinical symptoms and signs is required in order to diagnostically differentiate the subtypes. The overlap of configurations of symptoms and signs, compounded by multiple comorbidities (Graham et al. I996b, I999; Mitnitski et al. I997; Jellinger and Mitter-Ferstl 2003), represent key challenges to the etiological diagnosis of dementia.

In clinical practice the presence of one sign may not necessarily sound an alarm. Rather, the emergence of certain combinations of symptoms and signs characterizes a disorder. Clinicians meet this challenge by recognizing patterns of symptoms and signs. Our group showed, however, that diagnoses are not always distinguishable when based simply upon the presence or absence of these signs and symptoms; rather, it is conditional relationships among the symptoms and signs that form probabilities for a particular diagnosis and for more than one diagnosis within an individual. By establishing that diagnostic probabilities can be ascertained from identifying the co-occurrences of symptoms and signs, this approach illustrated what is foundational to clinical reasoning: symptoms and signs do not occur independently, but are conditional on each other.

While with the CSHA, I had established that the clinicians' diagnoses met 
the standardized criteria for dementia. This was done by developing a series of algorithms that initially mimicked the standardized text for dementia as set out in the DSM and ICD texts (Graham et al. 1996a). ${ }^{5}$ I later examined how signs and symptoms, which were recorded in the data, interrelated with one another (Graham et al. I996b, I996c). Importantly, these analyses revealed redundancies in diagnostic activity-more than one constellation of signs and symptoms can constitute a single diagnosis. The evidence that a single diagnosis can actually be derived from very different patterns of signs and symptoms brings us closer to the meanings of the anomalies and inconsistencies and atypical presentations that are characterized in the elderly.

Additionally, the semiological catalogs, the bundles of meaningful symptoms and signs that define a diagnosis of dementia, can be quite specific for a given clinician or specialty, while varying among clinical specialties. While "harmonization" of standards remains the mission of many international private and public agencies (presumably to reduce redundancies and the costly repetition of drug trials in each regulating country), this standardization will be at the cost of multiple variant diagnostic interpretations, each plausible and potentially revealing of unknown but important relationships that are worthy of further study. By calling for more, rather than reduced, opportunities for variability in clinical representations, I challenge a clinical epidemiological tradition of standardization and of analyzing or "reading" a database as if it were a telephone book. Instead, not wanting to limit potential diagnostic interpretations, I suggest that Umberto Eco's (I990) “encyclopedia” approach can be adapted to reading database texts. This is an unusual inductive approach to reading epidemiological databases, but it paves the way for novel possibilities for understanding dementia, as well as other heterogeneous disorders.

Dementia subsumes an already formed mind, adding to but also taking away from it. How these bits and pieces form relationships and mark the type of dementia is the subject herein. The effects of how different clinicians hearken, or call attention (Haraway 1997, 2IO), to the existence of particular signs or symptoms in creating the diagnosis is of importance, and so, too, is the evidence for co-occurrence and relationships among the elements used to classify the subtypes for dementia (for example, Alzheimer's diseases, dementia of the Lewy body type, vascular cognitive impairments, and frontotemporal dementias). As Dumont suggested in looking at social castes, order results from a consideration of value and, necessarily, context. Considering value and Leibniz's struggle to embrace difference in the whole (I986, 252), I looked to the data for the configurations formed by idea-values or value-ideas of clinicians about dementia (the belief-practice text). Illustrating an empirical fit with Leibniz's concept of the "whole," the interrelating signs and symptoms form (hierarchical) structures that underline the type and severity of the dementia. 
The statistical strength (probabilistic value and context) among them varies, marking a particular subtype or severity.

By looking for associations between the constellations of symptoms and signs in the differential diagnoses and severities found in our sample population (in the database text), my colleagues and I found that certain symptoms and signs were conditional upon one another in forming a particular diagnosis. With more than four hundred variables in the CSHA clinical data, we did not intend to analyze all possible relationships. Instead, fifty-six variables were selected on the basis of their suspected clinical relevance. Nineteen of these symptoms and signs showed statistically significant probabilities (frequencies) and variance across fifteen diagnostic categories, including no cognitive impairment, cognitive impairment but no dementia; mild, moderate, and severe forms of Alzheimer's disease and vascular dementia; four subtypes of possible Alzheimer's disease; Parkinson's dementia; unspecified other dementias; and unclassified. ${ }^{6}$

A synergy index was calculated from the number of significant connections (synergies) divided by the square root of the diagnostic sample size. The pattern of associations (the "coordination" of the items) varied according to the specific diagnosis. For example, as a given sign is present, the probability that another sign is present systematically increases ("synergism") or decreases ("antagonism”). Importantly, these relationships between the signs and symptoms fall apart, decreasing significantly as dementia progresses (Graham et al. I996b). Dementia progression and specific etiologies have characteristic patterns of decline and destruction from the strong synergy that exists between symptoms and signs for those with no cognitive impairment. Those with no cognitive impairment had many coordinations (that is, strong synergy). This synergy decreased in those with severe dementia, and there were intermediate pictures for mild and moderate forms. There was significant reduction (more than ten times) in the values of our synergy index in the severe Alzheimer's disease group compared with results for the no-cognitive-impairment group. Synergy reached a maximum value in the no-cognitive-impairment group (55.6), declining to 5.8 in those with severe Alzheimer's, 3.3 in those with severe vascular dementia, and 3.0 in those with Parkinson's dementia. There is a strong relationship between activities of daily living (basic personal tasks of everyday life) and instrumental activities of daily living (those found in independent living, for example, the ability to do one's own shopping). This synergy score dropped from 7.42 for those with no cognitive impairment to 2.64 for those with cognitive impairment not dementia (CIND), and from I.84 to I.I7 to 0.99 among those with mild, moderate, and severe Alzheimer's disease. Particular diagnoses give rise to discernible patterns of synergy and antagonism; the coordination of items in Alzheimer's disease is distinct from the coordination of items in 
vascular dementia, for example. The different configurations of signs and symptoms, buried in the CSHA database, reflect etiology and stage for frailty and cognitive aging (Mitnitski et al. 1997; Graham et al. 1999).

WHEN DIAGNOSTIC CATEGORIES can be disaggregated into the elements used to construct them, and the relations between these items are revealed, then culture and nature can be seen to comfortably coexist in relationships neither wholly natural nor cultural; nosology has what Latour (1993) might refer to as a "symmetrical" anthropological landscape, one that weaves both culture and biology. Each trope of clinical decision making is precipitated on some configuration of signs and symptoms that reveal themselves as distinct constellations. I suggest that any constellation of events has probabilistic dimensions, with different degrees of overlapping clusters of interconnected elements. The nosologies currently in use rely on hard categories; they cut up a degenerative process into segments that mask, rather than mirror, a plurality of different socioneurodegenerative processes (Lyman 1989; Davies 2004). Built-in redundancies mean that many different routes can be followed. As Tallis reminds us, these are people encountering a process in which "life becomes an impenetrable solitude of a series of disconnected moments" (personal communication), witnessed by involuntary egoism with the failure to engage in the organized interest of others. The demented person is conscious, yet his or her purposive actions give an enigmatic cast to a context no longer shared with others. Without memory, the sufferer does not experience shared continuity through time (Tallis 1996). And the current medical approach to determining hard diagnostic categories indeed also reflects this discontinuity. Having seen where the database text reveals relationships that are not articulated in the standardized criteria, let us turn now to what is buried in the belief-practices of medical mindscapes and clinical cultures that are diagnosing dementia.

\section{Medical Mindscapes}

I have suggested here that one can read the CSHA database as narrated stories by some seventy-six physicians representing five clinical specialties. These hidden and unintended stories provide us with an extraordinary view of the cultural activity of the diagnostic practices of clinicians. Shepherd, in examining the role played by British nosologists in psychiatric classification, noted that after considerable international work on the schizophrenias by the WHO's ICD, "it quickly became apparent that the major source of variation among experienced clinicians was the difference between their nosological schemata, all of which were subject to influence by the various schools of psychiatry" $(1994,3)$. But "culture is a perspective on reality, rather than a collection of categories marking differences among individuals" (Corin I994, IOI). The fervent activity 
directed at international standardization in case ascertainment and assessment of severity is an attempt to gain what Shepherd refers to as a "common language, a psychiatric Esperanto, [that] constitutes no more than a necessary prerequisite for a rationally-based nosology" (3).

The exercise of standardizing empirical evidence is intriguing, but it may well result in the reduction or loss of important details that provide us with the key to unlocking a terrain that presently remains illusive. While the idea of comorbid dementias, of an Alzheimerized Parkinson's or vascular dementia, existed (Emery and Oxman 1994), only more recently has evidence begun to corroborate the theory (Graham et al. I996b, Mitnitski et al. I997; Jellinger and Mitter-Ferstl 2003). Importantly, those standardizations use the probabilities or synergy coordinations between signs and symptoms that represented these emerging classifications (Graham et al. I996b; Mitnitski et al. I997; Graham et al. 1999).

In areas of medical diagnostics that are undergoing shifts in classification, such as that encountered among the evolving dementia etiologies, important information (which might be called empirical evidence but certainly is not necessarily limited to that epistemological terrain) is frequently overlooked, reduced to an incomprehensible construct, or lost entirely. Attention to this lost, or (adopting a genomic analogy) junk data (the butterfly effect in systems, where sensitivity to initial conditions result in a hurricane oceans away [Gleik I987]), might have led to innovative breakthroughs in understanding the particular syndrome and its many different manifestations in individual sufferers. For instance, those suffering dementia of the Lewy body type could be easily identifiable as "different from Alzheimer's disease" using the probabilistic method. They could be prevented from being prematurely hurried along a degenerative path when misdiagnosed with Alzheimer's disease and subsequently prescribed the neuroleptic medications harmful to those suffering Lewy body dementia that are commonly used in Alzheimer's sufferers.

Almeido-Filho and colleagues argue convincingly for inclusion of a cultural reading of nosology:

[V]ariations in disease categories and criteria through history and across cultures and societies make clear the lack of "objectivity" of diagnostic categories. Phenomena associated with mental health, disease and care must be conceived as historical, context-sensitive, fragmented, conflictive, dependent, and uncertain processes, therefore more efficiently modelled as open systems. In a particular social and cultural setting, the professional conception of such specific model-objects shall be the result of the application of a methodological practice equally context-sensitive, interactive and pluralistic (n.d., Io).

The symptoms and signs used by each clinician are based on the physician's 
training, reading, and clinical experience. This is information existing in the mindscape of all clinicians and is based on the material they have read and all the patients they have examined. It includes a whole range of attitudes that can be included in what epidemiologists call biases (Sackett 1979), which "sneak in" to the pursuit of objectivity (Huston I995; Klein et al. 1995). As noted by Corin, "The diagnosis only exists and has value in relation to the specific semiological system of the clinician" (Almeido-Filho et al. n.d., 9).

Empirical data do not always form the basis of nosology in psychiatry, and "consequently, the definition of discrete disorders remains an artifact of sometimes arbitrary criteria that leave the classification of milder and intermediate forms of distress ambiguous" (Kirmayer 1989, 327). As is done in much of the anthropological study of medicine, Kirmayer focuses particularly on the meaning of the symptoms to the patient, on how "culture influences symptoms from their inception." As a result of this focus, there is a valuable body of information on the profound cultural meanings of symptoms. Cultural variations in the manifestations of these symptoms are being addressed by the "new crosscultural psychiatry" and influence much of medical anthropology and psychiatry (Good and Good I98I; Kleinman I987, I988; Kirmayer I989; Littlewood I990), making room for alternative approaches to the exploration of eternally evolving concepts of clinical practice (for example, Eisenberg 1986, I995). The universality of disease categories continues to be questioned as epistemological considerations generate, in extreme instances, "a view of psychiatry as a cultural product of Western societies in the same way as are the diatonic scale and CocaCola. These products can be exported all over the world and may be appreciated by the local populace, but are no more valid than indigenous music or vegetables" (Leff I990, 305).

Even Kraepelin, a century ago, took a "far from dogmatic" position on the relationship between symptoms and disease etiology. He "accepted the existence of both psychological and biological factors and recognized that their nature and role were in many cases hypothetical or unknown" (Pichot 1994, 237). It was Kraepelin's essentialist ideal, which is described here by Pichot: "If we had at our disposal all the scientific facts, we could define the categories either by symptomatic, pathogenic, or etiological criteria, but the three resulting nosologies would be identical, a perfect correspondence between the three levels being postulated. Accordingly, if we do not yet have a sufficient knowledge of the mechanisms and the causes, the study of the symptoms, of their conditions of apparition, their nature, and their evolution will result in a 'natural' nosology" (236-237).

My work, presented in this chapter, focuses on the collection of symptoms and signs that are reported by physicians in the act of diagnosing dementia. While the examination of a patient is interpreted by clinicians as empirical evidence for their diagnostic opinion, it is also shaped by the conceptual tropes of 
their discipline. For the purpose of exploring how they place different weights, different interpretations of importance, on particular items or particular intertextual configurations of their observations of symptoms, signs, and behaviors in a person, I accepted their observations as facts in the world. I could thereby explore the potential to uncover the direction in which cultures of clinical specialties influence diagnostic practice. Whether this will provide a "greater understanding of the whole" by embracing difference will remain elusive until there is a shift from the existing categorical thinking to a dimensional approach that examines probabilities within the symptoms and signs.

Some earlier epidemiological surveys have used operational criteria for dementia that neglect the essential "social functioning" dimension in the definition of dementia (for example, Pfeffer, Afifi, and Chance i987; Evans et al. 1989). Responding to these studies, colleagues and I found that neuropsychologists and physicians had different but complementary approaches to diagnosing dementia. Diagnostic agreements were greater when the patient had higher education, while depression and lower 3MS scores in dementia sufferers decreased diagnostic consistency between the neuropsychologists and physicians (McKnight, Graham, and Rockwood I999). Neuropsychologists relied on performance ratings on the neuropsychological tests and less on functional activities (Larrea et al. 2000). There are differing approaches by clinical specialties to criterion selectivity. A continental divide that had existed between more socially engaged old-age psychiatry in the United Kingdom and a more psychoneurological approach in the United States had closed by the turn of the previous century as the hard facts of neurological signs have gained diagnostic supremacy over that of the social affect and general well-being of the person. The neurological brain attracted the medical attention of clinical specialists, while the psychosocial contextualized mind of people with dementia now goes largely ignored (Eastwood I990, I995; Eisenberg I986).

\section{Local Cultures of Medical Specialization}

Physicians use the inventory of tests that they learn in medical school as prisms through which they look at their patients. Even though they ostensibly examine patients using the same standardized criteria, they rely most strongly on the signs that they have skills in detecting and in the instruments that most efficiently and effectively assist them in achieving a diagnosis. While the voices of clinical medicine may appear united, I suggest that different paths that are taken toward achieving this goal are oriented around the ecology of the particular specialty or school. Even when it is manacled to the operational criteria and standardized protocol, we can see in evidence that the clinical world of dementia too is organized around different cultural percepts and worldviews.

Seventy-six physicians representing five areas of medical specialty-family 


\begin{tabular}{|c|c|c|c|c|c|c|}
\hline \multicolumn{7}{|c|}{$\begin{array}{l}\text { Characteristics of All People Receiving Clinical Assessment } \\
\qquad(\mathrm{n}=2,914) \text { by Clinical Specialty }\end{array}$} \\
\hline & $\begin{array}{l}\text { Family } \\
\text { practitioner }\end{array}$ & $\begin{array}{l}\text { General } \\
\text { internist }\end{array}$ & $\begin{array}{l}\text { Geria- } \\
\text { trician }\end{array}$ & $\begin{array}{c}\text { Neuro- } \\
\text { logist }\end{array}$ & $\begin{array}{l}\text { Psychia- } \\
\text { trist }\end{array}$ & All \\
\hline 3MS score & 66.3 & 66.2 & $62.3^{a, b, d}$ & 65.7 & $57.1^{a, b, c, d}$ & 64.0 \\
\hline Age & 81.6 & 82.2 & $82.5^{a, e}$ & 81.8 & 80.9 & 82.0 \\
\hline Education & $8.2^{b, c, d}$ & 9.1 & 9.0 & 8.8 & $8.2^{b, c}$ & 8.6 \\
\hline $\begin{array}{l}\text { Percentage living } \\
\text { in institution }\end{array}$ & 40.1 & 36.1 & $45.3^{a, b}$ & 43.9 & $52.8^{a, b, c}$ & 43.1 \\
\hline $\begin{array}{c}\text { Figures rep } \\
\text { comparisons }\end{array}$ & $\begin{array}{r}\text { present signi } \\
\text {, with }{ }^{a} \text { famil } \\
{ }^{d} \mathrm{n}\end{array}$ & $\begin{array}{l}\text { ficant diff } \\
\text { y practitio } \\
\text { eurologist }\end{array}$ & $\begin{array}{l}\text { ences, whe } \\
\text { rs; }{ }^{b} \text { generz } \\
\text { psychiatri }\end{array}$ & $\begin{array}{l}n \text { adjuste } \\
\text { I internis } \\
\text { sts }\end{array}$ & $\begin{array}{l}\text { for multiple } \\
\text { cgeriatricial }\end{array}$ & \\
\hline
\end{tabular}

medicine $(n=36)$, general internal medicine $(n=6)$, geriatric medicine $(n=$ $2 \mathrm{I})$, neurology $(n=8)$, and psychiatry $(n=5)$-performed the clinical assessments in the CSHA. There was very good diagnostic consistency among the physicians from across the country and extremely high concordance ( 98 percent) of their diagnoses with DSM-III-R criteria for dementia and NINCDS-ADRDA (92 percent) (Graham et al. I996a). A kappa measure for interrater reliability measured o.8I, for a near-perfect agreement. As the diagnosis was made more specific, however, from a comparison of dementia/not dementia, to dementia/ CIND/no impairment, to dementia subtyping, the consistency declined. Additionally, there were some differences in the patient populations seen by some clinical specialties. For example, 53 percent of the CSHA participants who were examined by psychiatrists were living in institutional care facilities, whereas the majority (6o percent) of people seen by family physicians lived in the community. In a U.S. study, Rybicki, Johnson, and Gorell (1995) found that primary care physicians were more likely to refer Parkinson's cases to a neurologist if the patient was younger, was male, had a private insurance plan, used health care more often than the norm, and used hospital-based clinics for their primary care. This selective referral bias remains an important deterrent to hospitalbased case-control studies. The randomized representative sample of elderly Canadians selected for the CSHA was meant to counter this form of systematic bias. Despite this study design, however, CSHA psychiatrists saw proportionately more institutionalized elderly than did the other physicians (although residence could be controlled in subsequent analyses). In general, their patients 
had a lower 3 MS score and lower education level than the people examined by the other study physicians (Table 4.I).

Considerable variation in specialist differential-diagnostic opinion became apparent. Neurologists diagnosed proportionately almost twice as many people with probable Alzheimer's disease than did psychiatrists, who, in turn, diagnosed two and a half times the proportion of vascular dementias compared with the neurologists, and about I.5 times more frequently made "other specific dementia” diagnoses (which include Parkinson's dementia, alcohol-related conditions, postinjury to the head, tumors, normal pressure hydrocephalus, frontal lobe disorder, Pick's disease). General internists and psychiatrists made proportionately fewer probable Alzheimer's disease diagnoses than the others, with internists identifying more people with possible Alzheimer's disease (which includes four distinct subcategories of atypical presentation, vascular components, Parkinsonism, and comorbidity) and psychiatrists finding vascular dementia at roughly three times the rate that neurologists made the same diagnosis in the community population and twice the rate in the institutionalized elderly.

General internists and neurologists diagnosed vascular dementia the least among the clinical specialties. The general internists were also least likely to place a person into an unclassifiable dementia category. Psychiatrists, by contrast, placed I5 percent of community-living elderly into this category, in comparison to an average rate of 7 percent for all physicians.

If we look to particular characteristics of the diagnostic patterns by the various clinical specialties for all people represented in the CSHA, including those with no cognitive impairment and those with cognitive impairment but not meeting dementia criteria (that is, CIND), we see some interesting differences. Even when controlling for residence, psychiatrists found significantly fewer people to be cognitively normal. Corroborating the findings of Wind and colleagues (1995), but different from what was found among German general practitioners who tended to overestimate impairment (Cooper, Bickel, Schäufele 1992), CSHA family practitioners and internists were less likely to make a dementia syndrome diagnosis than were the other specialists.

The people diagnosed as cognitively normal seemed to have relatively similar characteristics across examining specialists, although those seen by geriatricians and neurologists had higher cognitive scores, and there was a slightly greater proportion of institutionalized elderly seen by family practitioners than by geriatricians (Table 4.2). Among the people diagnosed with CIND (Graham et al. 1997), there were few differences associated with clinical specialty, although those examined by psychiatrists were younger than the people seen by geriatricians, and those seen by internists had higher education on average and a smaller proportion were institutionalized (Table 4.3). However, when we look at the people diagnosed with dementia (Table 4.4), those seen by the neurologists 


\begin{tabular}{|c|c|c|c|c|c|c|}
\hline \multicolumn{7}{|c|}{$\begin{array}{l}\text { TABLE } 4.2 \\
\text { Characteristics of People Diagnosed as Cognitively Normal } \\
(\mathbf{n = 9 2 1 )} \text { by Clinical Specialty }\end{array}$} \\
\hline & $\begin{array}{c}\text { Family } \\
\text { practitioner }\end{array}$ & $\begin{array}{l}\text { General } \\
\text { internist }\end{array}$ & $\begin{array}{l}\text { Geria- } \\
\text { trician }\end{array}$ & $\begin{array}{c}\text { Neuro- } \\
\text { logist }\end{array}$ & $\begin{array}{l}\text { Psychi- } \\
\text { atrist }\end{array}$ & All \\
\hline 3MS score & 82.8 & 82.8 & $86.2^{a, b}$ & $87.2^{a, b}$ & 85.6 & 84.6 \\
\hline Age & 79.8 & 80.7 & 80.0 & 80.3 & 80.6 & 80.1 \\
\hline Education & 8.6 & 9.7 & 9.7 & 10.2 & 8.9 & 9.2 \\
\hline $\begin{array}{l}\text { Percentage living } \\
\text { in institution }\end{array}$ & $21.8^{c}$ & 17.0 & 13.1 & 22.0 & 15.4 & 17.9 \\
\hline $\begin{array}{l}\text { Figures rep } \\
\text { comparisons, }\end{array}$ & $\begin{array}{l}\text { esent signifi } \\
\text { with }{ }^{a} \text { family } \\
{ }^{d} \text { ne }\end{array}$ & $\begin{array}{l}\text { cant diffe } \\
\text { practition } \\
\text { urologists }\end{array}$ & $\begin{array}{l}\text { nces, wh } \\
\text { rs; }{ }^{b} \text { gener } \\
\text { psychiatr }\end{array}$ & $\begin{array}{l}\mathrm{n} \text { adjuste } \\
\mathrm{l} \text { internis } \\
\text { th }\end{array}$ & $\begin{array}{l}\text { for multipl } \\
;{ }^{c} \text { geriatricia }\end{array}$ & \\
\hline
\end{tabular}

had a higher $3 \mathrm{MS}$ score than those examined by other specialists. The people seen by CSHA psychiatrists tended to be slightly younger; those examined by the geriatricians had, on average, a lower 3MS score for cognitive functioning along with a higher level of education.

Finally, Table 4.5 provides the probabilities of twenty-one symptoms and

\begin{tabular}{|c|c|c|c|c|c|c|}
\hline \multicolumn{7}{|c|}{$\begin{array}{c}\text { Characteristics of People Diagnosed as Cognitively Impaired but Not } \\
\text { Dementia (CIND) }(n=861) \text { by Clinical Specialty }\end{array}$} \\
\hline & $\begin{array}{l}\text { Family } \\
\text { practitioner }\end{array}$ & $\begin{array}{l}\text { General } \\
\text { internist }\end{array}$ & $\begin{array}{l}\text { Geria- } \\
\text { trician }\end{array}$ & $\begin{array}{c}\text { Neuro- } \\
\text { logist }\end{array}$ & $\begin{array}{c}\text { Psychi- } \\
\text { atrist }\end{array}$ & All \\
\hline 3MS score & 70.5 & 69.6 & 72.1 & 71.0 & 71.5 & 71.1 \\
\hline Age & 81.3 & 81.3 & 81.8 & 80.5 & $79.4^{c}$ & 81.3 \\
\hline Education & 7.9 & $9.1^{a, d}$ & 8.2 & 7.7 & 8.1 & 8.1 \\
\hline $\begin{array}{l}\text { Percentage living } \\
\text { in institution }\end{array}$ & 42.0 & $30.4^{c}$ & 44.7 & 39.1 & 45.5 & 41.8 \\
\hline $\begin{array}{c}\text { Figures rep } \\
\text { comparisons }\end{array}$ & $\begin{array}{l}\text { oresent signi } \\
\text { with }{ }^{a} \text { family } \\
{ }^{d} \mathrm{n}\end{array}$ & $\begin{array}{l}\text { ificant differ } \\
\text { y practition } \\
\text { eurologists; }\end{array}$ & $\begin{array}{l}\text { ences, wh } \\
\text { ers; }{ }^{b} \text { gener } \\
\text { epsychiat }\end{array}$ & $\begin{array}{l}n \text { adjuste } \\
l \text { internis } \\
\text { sts }\end{array}$ & $\begin{array}{l}\text { or multi } \\
\text { geriatric }\end{array}$ & \\
\hline
\end{tabular}


TABLE 4.4

\section{Characteristics of People Diagnosed with Dementia $(n=1,132)$ by Clinical Specialty}

\begin{tabular}{lcccccc} 
& $\begin{array}{c}\text { Family } \\
\text { practitioner }\end{array}$ & $\begin{array}{c}\text { General } \\
\text { internist }\end{array}$ & $\begin{array}{c}\text { Geria- } \\
\text { trician }\end{array}$ & $\begin{array}{c}\text { Neuro- } \\
\text { logist }\end{array}$ & $\begin{array}{c}\text { Psychi- } \\
\text { atrist }\end{array}$ & All \\
\hline 3MS score & 41.4 & 44.3 & $36.9^{a, b, d}$ & $46.3^{\mathrm{e}}$ & 36.9 & 40.0 \\
Age & 83.9 & 84.5 & 84.7 & 83.8 & $82.0^{a, b, c, d}$ & 84.1 \\
$\begin{array}{l}\text { Education } \\
\begin{array}{l}\text { Percentage living } \\
\quad \text { in institution }\end{array}\end{array}$ & 8.0 & 8.4 & $9.0^{a, e}$ & 8.6 & 8.0 & 8.5 \\
& $58.7^{c, e}$ & 61.0 & 68.9 & 61.4 & 70.3 & 64.5 \\
\hline
\end{tabular}

Figures represent significant differences, when adjusted for multiple comparisons, with afamily practitioners; ${ }^{b}$ general internists; 'cgeriatricians; ${ }^{d}$ neurologists; ${ }^{e}$ psychiatrists

signs assessed for everyone diagnosed with dementia by the specialty of those diagnosing. An additional four demographic items-the 3MS score, age, years of education, and percentage of this study population living in an institution-are also provided. Probabilities that were significantly different from those of the other clinical specialist groupings are identified. Even controlling for multiple comparison, only three items show no variation between the clinical specialties. These are impaired abstract thinking and impaired judgment, both of which remain consistently high in all people suffering from dementia, and paranoid behavior.

\section{Conclusions}

Addressing the cultural dimensions of the experience of Alzheimer's disease and of other dementias for the sufferer and caregivers was not the goal of this chapter (see, instead, e.g. Henderson I990; Gubrium I986; Cohen I995; Herskovits 1995; as well as other chapters in this volume). Estes and Binney (I99I) have described in detail many of the arguments against the biomedicalization of aging that have privileged the clinical over political and ontological constructs. It is precisely these clinical constructs that I have targeted in my novel approach to dementia, for these constructs are the tropes by means of which physicians make diagnoses. I have shown, however, that these clinical constructs are not separate from cultural practices and beliefs by focusing on what clinicians use to assemble a diagnosis of dementia and its subtypes. 


\begin{tabular}{|c|c|c|c|c|c|c|}
\hline \multirow[b]{2}{*}{ SYMPTOM } & $\begin{array}{l}\text { mptoms fo } \\
\text { Specialty }\end{array}$ & $\begin{array}{r}\text { TABLE } 4 . \\
\text { oll Diag } \\
\text { (Number } 0\end{array}$ & $\begin{array}{l}5 \\
\text { of Diagno }\end{array}$ & $\begin{array}{l}\text { Dementi } \\
\text { oses) }\end{array}$ & \multirow[b]{2}{*}{$\begin{array}{l}\text { Psychi- } \\
\text { atrist } \\
(n=111)\end{array}$} & \multirow[b]{2}{*}{$\begin{array}{c}\text { TOTAL } \\
(n=1132)\end{array}$} \\
\hline & $\begin{array}{c}\text { Family } \\
\text { Practitioner } \\
(n=322)\end{array}$ & $\begin{array}{l}\text { Internist } \\
(n=100)\end{array}$ & $\begin{array}{l}\text { Geria- } \\
\text { trician } \\
(n=454)\end{array}$ & $\begin{array}{l}\text { Neuro- } \\
\text { logist } \\
(n=145)\end{array}$ & & \\
\hline Facial bradykinesia & .132 & .055 & $.141^{b}$ & $.211^{a, b}$ & $.243^{a, b, c}$ & .149 \\
\hline Limb bradykinesia & .190 & $.074^{a, d, e}$ & .145 & $.285^{a, c}$ & .206 & .176 \\
\hline Limb tone & .341 & $.187^{a, c, d, e}$ & e $.467^{a, d}$ & .344 & .374 & .383 \\
\hline Agnosia & $.444^{b, d, e}$ & .179 & $.471^{b, d, e}$ & $=.321$ & .250 & .406 \\
\hline Memory impairment & .917 & $1.00^{a, c, d}$ & .921 & $.864^{c, e}$ & .949 & .923 \\
\hline Impaired focal signs & .329 & $.200^{a, c, e}$ & .373 & $.252^{c, e}$ & .436 & .336 \\
\hline History of stroke & .245 & .282 & .308 & $.172^{c, e}$ & .317 & .272 \\
\hline Arterial hypertension & .351 & $.229^{c}$ & .383 & .294 & .296 & .340 \\
\hline $\begin{array}{l}\text { Impaired abstract } \\
\text { thinking }\end{array}$ & .893 & .862 & .929 & .882 & .913 & .905 \\
\hline Impaired judgment & .808 & .785 & .835 & .784 & .807 & .814 \\
\hline $\begin{array}{l}\text { Diminished activities } \\
\text { of daily living }\end{array}$ & .554 & .586 & $.662^{a, d}$ & .472 & $.682^{a, d}$ & .602 \\
\hline Emotional incontinence & .086 & .109 & $.210^{a, b, d}$ & .049 & $.208^{a, b, d}$ & .146 \\
\hline Somatic complaints & .072 & $.224^{a, c, d}$ & .068 & .128 & $.196^{a, c}$ & .104 \\
\hline Depression (MD exam) & $.096^{e}$ & .139 & $.072^{d, e}$ & .167 & .233 & .113 \\
\hline Depression (CAMDEX) & .419 & $.541^{a, c, d}$ & .378 & .317 & $.548^{a, c, d}$ & .413 \\
\hline Episodes of agitation & .190 & .207 & $.330^{a, b, d}$ & $\begin{array}{l}d \quad .119 \\
\text { la }\end{array}$ & $.371^{a, b, d}$ & .260 \\
\hline Personality changes & .753 & .788 & .755 & $.634^{a, b, c,}$ & , e.835 & .750 \\
\hline $\begin{array}{l}\text { Difficulties with } \\
\text { everyday activities }\end{array}$ & .793 & .788 & $.860^{a, d}$ & .731 & .809 & .813 \\
\hline Paranoid & .231 & .278 & .231 & .201 & .278 & .236 \\
\hline $\begin{array}{l}\text { Cerebrovascular } \\
\text { problems }\end{array}$ & .436 & .404 & .429 & $.273^{a, b, d}$ & t,e $.608^{a, b, c}$ & .427 \\
\hline Mobility difficulties & .663 & .719 & .708 & $.515^{a, b, c, e}$ & e. .722 & .674 \\
\hline 3MS score & 41.4 & 44.3 & $36.9^{a, b, d}$ & 46.3 & $36.9^{d}$ & 40.0 \\
\hline Age (years) & 83.9 & 84.5 & 84.7 & 83.8 & $82.0^{a, b, c}$ & $, c, d 84.1$ \\
\hline Education (years) & 8.0 & 8.4 & $9.0^{a, e}$ & 8.6 & 8.0 & 8.5 \\
\hline $\begin{array}{l}\text { Percentage living } \\
\text { in institution }\end{array}$ & $58.7^{c, e}$ & 61.0 & 68.9 & 61.4 & 70.3 & 64.5 \\
\hline $\begin{array}{l}\text { Figures represen } \\
\text { comparisons, with }\end{array}$ & $\begin{array}{l}\text { nt significar } \\
{ }^{\text {afamily pra }} \\
{ }^{d} \text { neuro }\end{array}$ & $\begin{array}{l}\text { actitioners; }{ }^{b} \\
\text { logists; }{ }^{e} \text { psy }\end{array}$ & $\begin{array}{l}\text { ces, when a } \\
\text { bgeneral in } \\
\text { ychiatrists }\end{array}$ & $\begin{array}{l}\text { adjusted fo } \\
\text { nternists; }\end{array}$ & $\begin{array}{l}\text { or multiple } \\
\text { cgeriatricia }\end{array}$ & le \\
\hline
\end{tabular}


In this chapter I present various diagnostic approaches to dementia and its subtyping by physicians, carried out in clinical practice, collected, and then inscribed in a database text. Historically, anthropology has kept distant from broken bones and "organic" disease in examining health, illness, and sickness. In taking on a syndrome that can be explored as disease, illness, and sickness (Young 1982), I advance here a methodology that employs an anthropology of diagnostic process, examining the physician's own data for hidden relationships that usually go without saying. In the process, I reveal potentially useful "bundles of criteria" specific to the refined skills and training of subcultures within clinical medicine.

Exploring the manner in which senile dementia is classified by expert research clinicians places emphasis on how they "distinguish-choose-positassemble-count-speak" (Castoriadis 1987) through the data they report. The choices they make often reveal the underlying premises with which they engage in diagnostic practice. The assemblage of signs, symptoms, and behaviors collected, cataloged, and interpreted by clinicians in diagnosing dementia, and the clinical diagnostic decision-making process in general are represented in a database text. I have elucidated this text using what Eco refers to as an encyclopaedia perspective. The database, I suggest, represents a "systematic assemblage of the key configurations which connect elements in a given culture," which, like an encyclopaedia, "can be seen as providing the major codes and key categories that prevail in a culture, including the preferential schemas that determine the architecture of that culture, and the semantic web that links cultural elements together" (Bibeau and Corin I994, IO).

I have shown that we can empirically draw the intertextual relational properties of the individual items that make up the constituent units of diagnostic practice. Symptoms and signs gain meaning via their interactions, through their synergies and antagonisms. Furthermore, they can be used as building blocks in the construction of the social imaginary of medical mindscapes. They hold within their relationships to one another hierarchical orderings that represent particular distinctive expressions of etiology and neurodegeneration. My methodology develops a preliminary and exploratory heuristic instrument (an algorithm with synergies) that produces a differential diagnosis for dementia based upon clinical decision-making probabilities and groupings of clinical factors. The methodology has been used to develop more refined definitions through access to bodies of information that are concealed in databases. New and evolving categories of dementia can be probabilistically estimated on the basis of already existing data. It can thereby be used to demonstrate the conceptual shifts and overlaps at the level of diagnostic discursive practice (Foucault I972, 60) and the construction of illness as an object of diagnostic activity (Good 1994, 66).

Particular tropes direct clinical specialists in their choice of configurations 
of symptoms and signs. Psychiatrists look more carefully at the affective qualities of their patients, on depression, somatic complaints, agitation, emotions. The context of social functioning is of some importance for psychiatrists. Neurologists examine the neurological signs, activities, and functioning, while affective and personality characteristics seem less important for them. Geriatricians focus on functional and global concerns; their patients' competence in activities of daily living, that is, their ability to perform everyday tasks, is clearly significant, but so too (and no doubt related to the individual's capacity to function) are configurations of neurological components. These additional elements in the geriatrician's toolkit likely reflect geriatric medicine in Canada, where it is a subspecialty in which the practitioner focuses on geriatrics after having already specialized in internal medicine. General internists appear to represent a more diverse group, placing less focus on the "aging" individual and more on the mechanistic systemic signs and symptoms; family practitioners consider the management and care of the patient and the patient's family and seem to be less concerned with a specific etiological diagnosis and more interested in the ongoing ability of the aging individual to continue to function in his or her everyday life.

Rather than follow international harmonization attempts to funnel the perspectives of these different practical approaches into one reduced set of criteria that can be universally applied to all, in this chapter I make a case that, instead, we might be better served by embracing differences in diagnostic practice. Although a standardized toolkit has practical utility in addressing common concerns and public-health policy, much might be gained by allowing many different approaches. The loss of information when a standardized approach is forged should be avoided, for it leads to items that go unrecorded, which cannot then be reflected upon, and which are removed from the landscape of possibilities. These lost bits and pieces might have had the potential to later answer the questions that further our inquiry and knowledge.

I have described how clinicians and the medical-scientific community interpret dementia through belief-practices that are not often consciously known. I believe that the approach I have taken as a means to understand this represents a similar decision-making model that the physicians themselves use. I have, however, found no other such attempts to examine the probabilistic relationships of the meaningful units of diagnostic activity. Clinicians' own texts, comparing their standardized diagnostic criteria to their practices as recorded in their databases, were used to unravel the constellation of elements (signs, symptoms) of diagnostic meaning. This approach includes a multiplicity of voices of clinicians diagnosing dementia, their interpretations of the particular tests, and technologies used distinctively by them to identify symptoms and signs that represent meaningful aspects of some disease process.

Through a recognition of databases, dementia, and diagnostic processes as 
technoscientific objects, the tension between structure and agency, that is, the relationships between the databases, as well as the databases themselves, have been examined. I relied on the epidemiological database created by these same scientists and clinicians for disclosure and understanding. This serves both to facilitate their important quest to diagnose more accurately and efficiently, while providing us with the information on the discourse they engage in to go about this task. The relationships between the signs and symptoms, what I called synergism and antagonism, were described and used ontologically to construct other diagnostic narratives. Multiple comorbidities and severities were thereby illustrated.

My approach addresses the issues of standardization, reliability, and validity that are inherent in epidemiological, clinical, and anthropological interpretations; and in the process of advancing the clinical-medical-scientific inquiry into the syndrome of dementia and its differential diagnosis, I elucidate elements and aspects of clinical culture in diagnostic practice. Evidence of several paths to diagnosis were provided, incorporating many different configurations of symptoms and signs in diverse semiological catalogs. If this argument is sound, then perhaps we should consider a reexamination of the importance of emphasizing the standardization of diagnoses and explore instead the wealth of information contained in the plurality of clinical approaches that are currently hidden under the guise of standardization.

\section{NOTES}

I. The CSHA clinical exam had been designed in consultation with several international studies, including a World Health Organization (WHO) study on dementia (Amaducci and Baldereschi 199I), and with the Consortium to Establish a Registry for Alzheimer's Disease (CERAD) project in the United States (Heyman 1990), whose work continues and has been widely influential in international studies (e.g., Prince et al. 2003). During the I99os, I consulted extensively with an international group of expert dementia diagnosticians, which included a team of Canadian neurologists, geriatricians, psychiatrists, neuropsychologists, and epidemiologists from across Canada (Graham et al. 1996a). I also met with investigators in the Eurodem (European Community Concerted Action Epidemiology and Prevention of Dementia) and the U.K. Medical Research Council (MRC) Multicentre Study of Cognitive Function and Ageing (Cooper and Bickel I984; Copeland et al. 1987).

2. National Institute of Neuological and Communicative Diseases and Stroke/ Alzheimer's Disease and Related Disorders Association.

3. Ironically, the banquet menu at this meeting of the invited leading international dementia experts, held during the height of the variant Creutzfeld-Jacob (mad cow) epidemic in the United Kingdom, included a robust serving of haggis.

4. Identification of a population experiencing some form of mild cognitive impairment that did not meet the dementia criteria (CIND) in my Lancet article in 1997 expanded the Canadian prevalence rates from 8 percent of the population over sixty-five years old with some form of dementia to 25 percent of this same population having some form of cognitive impairment. Despite my emphasis that CIND was a heuristic 
category, identified for research purposes only, its market potential for the fastemerging therapeutic products was not lost on the pharmaceutical industry, or on medical researchers who were funded for clinical trials. I had developed qualitative and ethnographic methods for an approach to assess dementia progression and treatment responses from the perspectives of the sufferers and their caregivers (Joffres, Graham, and Rockwood 2000; Rockwood et al. 2002). Attention to individual problem areas provides a detailed inventory of events that allow for a more meaningful interpretation than that provided by the usual psychometric characteristics, as well as important references for counseling patients with what was being clinically referred to in research circles at the time and increasingly marketed as the "new entity of pharmacologically treated dementia." Patient expectations are marketed by pharmaceutical companies (Graham 20OI). My most recent work has turned to an exploration of the moral basis of profit and drug regulation (Graham 200I, 2003). A primary drive behind diagnostics is therapeutics, which has multiple stakeholders, including corporate interests. The life history of a pharmaceutical involves a relationship between finance, research, and marketing.

5. For example, a diagnosis of dementia demands that a series of criteria be met, including memory loss, a decline from a previous higher level of functioning, and cognitive loss that affects social functioning. All these items had to be met in the clinical diagnoses to establish consistency with the diagnostic criteria.

6. The following symptoms and signs used are for the synergy index (from Graham et al. 1996b). Clinical history: arterial hypertension, episodes of agitation, stroke, memory, mood (for example, anxiety, sadness); CAMDEX (informant interview): clouding/delirium; and neurological examination: facial bradykinesia, limb bradykinesia, limb tone, neck tone, muscle bulk, strength, posture, limb coordination, gait pattern, resting tremor, action tremor, voice, focal signs.

\section{REFERENCES}

Adelman, Richard C. 1995. "The Alzheimerization of Aging." Gerontologist 35 (4): 526-532. Agamben, Giorgio. 1998. Homo Sacer: Sovereign Power and Bare Life. Stanford: Stanford University Press.

Almeido-Filho, Naomar, Ellen Corin, Gilles Bibeau, and Elizabeth Uchôa. n.d. "The Systems of Signs, Meanings, and Practices Related to Mental Health: From Epistemology to Methodology."

Amaducci, L., and M. Baldereschi. 1997. "Criteria for the Clinical Diagnosis of Alzheimer's Disease: Transcultural Aspects.” In Alzheimer's Disease: From Molecular Biology to Therapy, ed. Robert E. Becker and Ezio Giacobini. Cambridge: Birkhäuser.

American Psychiatric Association. 1994. Diagnostic and Statistical Manual of Mental Disorders. 4th ed. Washington, D.C.: American Psychiatric Association.

—. 1987. Diagnostic and Statistical Manual of Mental Disorders. 3d ed. rev. Washington, D.C.: American Psychiatric Association.

Appadurai, Arjun. 1986. The Social Life of Things: Commodities in Cultural Perspective. Cambridge, U.K.: Cambridge University Press.

Bibeau, Gilles, and Ellen Corin. 1994. "From Submission to the Text to Interpretive Violence." In Beyond Textuality: Asceticism and Violence in Anthropological Interpretation, ed. Gilles Bibeau and Ellen Corin. New York: Mouton de Gruyter.

Bibeau, Gilles, Janice Graham, and Usher Fleising. Forthcoming. "Bioscience and Biotechnology under Ethnographic Surveillance: Where Stand Canadian Medical Anthro- 
pologists?" In Anthropologie de la santé et de la maladie: Perspectives internationales et enjeux contemporain, ed. Francine Saillant and Serge Genest. Presses de l'Université Laval (French edition). Anthropology of Health and Illness: International Perspectives (submitted for the English edition).

Blennow K., A. Wallin, and C. G. Gottfries. 1994. "Clinical Subgroups of Alzheimer's Disease.” In Dementia: Presentations, Differential Diagnosis, and Nosology, ed. V.O.B. Emery and T. E. Oxman. Baltimore: Johns Hopkins University Press.

Bowler, John V., and Vladimir Hachinksi. 2003. Vascular Cognitive Impairment: Treatable Dementia. Oxford: Oxford University Press.

Canadian Study of Health and Aging. 1994. "The Canadian Study of Health and Aging: Study Methods and Prevalence of Dementia." Canadian Medical Association Journal I50:899913.

Canadian Study of Health and Aging Working Group: I. Hill et al. 200o. "The Incidence of Dementia in Canada." Neurology 55:66-73.

Casti, John L. 1990. Searching for Certainty: What Scientists Can Know about the Future. New York: William Morrow.

Castoriadis, Cornelius. 1987. The Imaginary Institution of Society. Cambridge, Mass.: MIT Press. (Orig. pub. 1975.)

Chui H. C., J. I. Victoroff, D. Margolin, W. Jagust, R. Shankle, and R. Katzman. I992. "Criteria for the Diagnosis of Ischemic Vascular Dementia Proposed by the State of California Alzheimer's Disease Diagnostic and Treatment Centers." Neurology 42:473-480.

Cohen, Lawrence. 1995. "Toward an Anthropology of Senility: Anger, Weakness, and Alzheimer's in Banaras, India." Medical Anthropology Quarterly 9 (3): 3I4-334.

Cooper, Brian, and Horst Bickel. 1984. "Population Screening and the Early Detection of Dementing Disorders in Old Age: A Review." Psychological Medicine I4:8I-95.

Cooper, Brian, Horst Bickel, and Marina Schäufele. 1992. "The Ability of General Practitioners to Detect Dementia and Cognitive Impairment in Their Elderly Patients: A Study in Mannheim." International Journal of Geriatric Psychiatry 7:59I-598.

Copeland J.R.M., M. J. Gurland, M. E. Dewey, M. J. Kelleher, A.M.R. Smith, and I.A. Davidson. 1987. "Is There More Dementia, Depression, and Neurosis in New York? A Comparative Study of the Elderly in New York and London Using the Computer Diagnosis AGECAT." British Journal of Psychiatry I5I:466-473.

Corin, Ellen. 1994. "The Social and Cultural Matrix of Health and Disease." In Why Are Some People Healthy and Others Not? The Determinants of Health in Populations, ed. Robert G. Evans, Morris L. Barer, and Theodore R. Marmor. New York: Aldine de Gruyter.

Davies, D. H. 2004. "Dementia: Sociological and Philosophical Constructions." Social Science and Medicine 58 (2): 369-378.

Dumont, Louis. 1986. Essays on Individualism: Modern Ideology in Anthropological Perspective. Chicago: University of Chicago Press.

Eastwood, M. Robin. 1990. "Who Owns the Brain?" Psychiatric Bulletin I4:353-355.

—_. I995. "Adieu to Alzheimer?" Canadian Journal of Psychiatry 39:25I-252.

Eco, Umberto. 1990. The Limits of Interpretation. Bloomington: Indiana University Press.

Eisenberg, Leon. 1986. "Mindlessness and Brainlessness in Psychiatry." British Journal of Psychiatry I48:497-508.

— . 1995. "The Social Construction of the Human Brain." American Journal of Psychiatry I52:I563-I575.

Emery, V.O.B., and T. E. Oxman. 1994. "The Spectra of Dementia." In Dementia: Presentations, Differential Diagnosis, and Nosology, ed. V.O.B. Emery and T. E. Oxman. Baltimore: Johns Hopkins University Press. 
Erkinjuntti, T., V. C. Hachinski, and R. Sulkava. 1994. "Alzheimer's Disease and Vascular Dementia." In Dementia: Presentations, Differential Diagnosis, and Nosology, ed. V.O.B. Emery and T. E. Oxman. Baltimore: Johns Hopkins University Press.

Erkinjuntti T., G. Roman, S. Gauthier, H. Feldman, and K. Rockwood. 2004. "Emerging Therapies for Vascular Dementia and Vascular Cognitive Impairment." Stroke 35 (4): IOIO-IOI7.

Estes, Carol L., and Elizabeth A. Binney. 1991. "The Biomedicalization of Aging: Dangers and Dilemmas." In Critical Perspectives on Aging: The Political and Moral Economy of Growing Old, ed. Meredith Minkler and Carol L. Estes. Amityville, N.Y.: Baywood.

Evans, D. A., H. Funkelsteim, M. S. Albert, P. A. Scherr, N. R. Cook, M. J. Chown, L. E. Hebert, C. H. Hennekens, and J. O. Taylor. 1989. "Prevalence of Alzheimer's Disease in a Community Population of Older Persons." Journal of the American Medical Association 262:255I-2556.

Fox, Patrick. 1989. "From Senility to Alzheimer's Disease: The Rise of the Alzheimer's Disease Movement." Milbank Quarterly 67:58-IO2.

Foucault, Michel. 1972. The Archaeology of Knowledge and the Discourse of Language. New York: Pantheon Books.

Friedrich, Paul. 1986. The Language Parallax: Linguistics, Relativism, and Poetic Creativity. Austin: University of Texas Press.

Gleick, James. 1987. Chaos: Making a New Science. Penguin.

Good, Byron J. 1994. Medicine, Rationality, and Experience: An Anthropological Perspective. Cambridge, U.K.: Cambridge University Press.

Good, Byron J., and Mary-Jo Delvecchio Good. 1981. "The Meaning of Symptoms: A Cultural Hermeneutic Model for Clinical Practice." In The Relevance of Social Science for Medicine, ed. L. Eisenberg and A. Kleinman. Dordrecht, Netherlands: D. Reidel.

Graham, Janice E. 1996. "Diagnosing Dementia: Signs, Symptoms, and Meaning." Ph.D. diss., University of Montreal, Quebec.

Graham, Janice. 20oI. "Harbinger of Hope or Commodity Fetishism: Re-cognizing Dementia in an Age of Therapeutic Agents." International Psychogeriatrics I3 (2): I3I-I34.

Graham, Janice. 2003. "Creating Hope and Commodifying Disease: Redefining Dementia." International Psychogeriatrics I5, no. 2:S90-9I.

Graham, Janice. Forthcoming. "If Meaning Counted: Measuring A/effect in Clinical Therapies." In revision for Culture, Medicine and Psychiatry.

Graham J. E., K. Rockwood, L. Beattie, I. McDowell, R. Eastwood, and S. Gauthier. I996a. "Standardization of the Diagnosis of Dementia in the Canadian Study of Health and Aging." Neuroepidemiology 15:246-256.

Graham J. E., A. Mitnitski, A. Mogilner, D. Gauvreau, and K. Rockwood. 1996b. "Symptoms and Signs in Dementia: Synergy and Antagonism." Dementia 7:33I-335.

—. I996c. "An Algorithmic Approach to the Differential Diagnosis of Dementia." Dementia 7:324-330.

Graham J. E., K. Rockwood, B. L. Beattie, R. Eastwood, S. Gauthier, H. Tuokko, and I. McDowell. 1997. "Prevalence and Severity of Cognitive Impairment with and without Dementia in an Elderly Population.” Lancet 349:I793-I796.

Graham J. E., A. B. Mitnitski, A. J. Mogilner, and K. Rockwood. I999. "The Dynamics of Cognitive Aging: Distinguishing Functional Age and Disease from Chronological Age in a Population." American Journal of Epidemiology I5O (IO): IO45-IO54.

Gubrium, Jaber F. 1986. Oldtimers and Alzheimer's: The Descriptive Organization of Senility. Greenwich, Conn.: JAI Press. 
Hachinksi, Vladimir. I992. "Preventable Senility: A Call for Action Against the Vascular Dementias.” Lancet 340:645-648.

—. I994. "Vascular Dementia: A Radical Redefinition.” Dementia 5:I30-I32.

Hanks, W. F. I989. Text and Textuality. Annual Review of Anthropology I8:95-I27.

—. I994. "Vascular Dementia: A Radical Redefinition." Dementia 5:I30-I32.

Haraway, Donna J. I997. Modest-Witness@Second-Millenium. Femaleman-Meets-Oncomouse: Feminism and Technoscience. New York: Routledge.

Henderson, J. Neil. I990. "Alzheimer's Disease in Cultural Context." In The Cultural Context of Aging: Worldwide Perspectives, ed. J. Sokolovsky. Westport, Conn: Bergin and Garvey.

Herskovits, Elizabeth. I995. "Struggling over Subjectivity: Debates about the "Self" and Alzheimer's Disease.” Medical Anthropology Quarterly 9 (2): I46-I64.

Heyman, A., G. G. Fillenbaum, and S. S. Mirra. I990. "Consortium to Establish a Registry for Alzheimer's Disease (CERAD): Clinical, Neuropsychological, and Neuropathological Components." Aging 2 (4) :4I5-424.

Huston, Patricia. I995. "The Pursuit of Objectivity." Editorial. Canadian Medical Association Journal I53 (6): 735.

Jellinger, K. A., and Erich Mitter-Ferstl. 2003. "The Impact of Cerebrovascular Lesions in Alzheimer's Disease.” Journal of Neurology 250:IO5O-IO55.

Joffres, Christine, Janice Graham, and Kenneth Rockwood. 200o. "A Qualitative Analysis of the Clinician Interview-Based Impression of Change (Plus): Methodological Issues and Implications of Clinical Research.” International Psychogeriatrics I2 (3): 4OI-4I5.

Keenan, Thomas. 1997. Fables of Responsibility: Aberrations and Predicament in Ethics and Politics. Stanford: Stanford University Press.

Klein, Michael C., Janus Kaczorowski, James M. Robbins, Robert J. Gauthier, Sally Helme Jorgensen, and Arvina K. Joshi. I995. "Physicians' Beliefs and Behaviour During a Randomized Controlled Trial of Episiotomy: Consequences for Women and Their Care." Canadian Medical Association Journal I53 (6): 769-779.

Kleinman, Arthur. 1987. "Anthropology and Psychiatry: The Role of Culture in Cross-Cultural Research on Illness.” British Journal of Psychiatry I5I:447-454.

- I988. Rethinking Psychiatry: From Culture Category to Personal Experience. New York: Free Press.

Kirmayer, Laurence J. I989. "Cultural Variations in the Response to Psychiatric Disorders and Emotional Distress." Social Science and Medicine 29:327-339.

Lambek, Michael. I99I. Tryin' to Make It Real, but Compared to What? Culture II (I-2): 43-5I.

Larrea, F. A., J. D. Fisk, J. E. Graham, and K. Stadnyk. 200o. "Prevalence of Cognitive Impairment and Dementia as Defined by Neuropsychological Test Performance." Neuroepidemiology I9:I2I-I29.

Latour, Bruno. 1993. We Have Never Been Modern. Cambridge, Mass.: Harvard University Press.

Latour, Bruno, and Steven Woolgar. 1986. Laboratory Life: The Construction of Scientific Facts. Princeton: Princeton University Press.

Leff, Julian. I990. "The 'New Cross-Cultural Psychiatry': A Case of the Baby and the Bathwater." British Journal of Psychiatry 156:305-307.

Littlewood, Roland. I990. "From Categories to Contexts: A Decade of the 'New CrossCultural Psychiatry." British Journal of Psychiatry 156:308-327.

Lyman, Karen A. 1989 "Bringing the Social Back In: A Critique of the Biomedicalization of Dementia.” Gerontologist 29 (5): 597-605.

The Lund and Manchester Groups. I994. "Clinical and Neuropathological Criteria for 
Frontotemporal Dementia: Consensus Statement." Journal of Neurology, Neurosurgery, and Psychiatry 57:416-4I8.

Maranda, Pierre. 1994. "Beyond Postmodernism: Resonant Anthropology." In Beyond Textuality, ed. Gilles Bibeau and Ellen Corin. New York: Mouton de Gruyter.

McKhann, G., D. Drachman, M. Folstein, R. Katzman, D. Price, and E. M. Stadlan. 1984. "Clinical Diagnosis of Alzheimer's Disease: Report of the NINCDS-ADRDA Work Group Under the Auspices of Department of Health and Human Services Task Force on Alzheimer's Disease." Neurology 34:939-944.

McKeith, I., R. H. Perry, A. F. Fairbairn, S. Jabeen, and E. K. Perry. 1992. "Operational Criteria for Senile Dementia of Lewy Body Type.” Psychological Medicine 22:91I-922.

MacKnight, C., J. E. Graham, and K. Rockwood. 1999. "Factors Associated with Inconsistent Diagnosis of Dementia between Physicians and Neuropsychologists." Journal of the American Geriatrics Society 47:I294-I299.

Mitnitski, A. B., J. E. Graham, A. J. Mogilner, and K. Rockwood. 1997. "Vector Diagnostics in Dementia Derived from Bayes’ Theorem.” American Journal of Epidemiology I46:665$67 \mathrm{I}$.

Nyenhuis, D. L., and P. B. Gorelick. 1998. "Vascular Dementia: A Contemporary Review of Epidemiology, Diagnosis, Prevention, and Treatment." Journal of the American Geriatrics Society 46 (II): I437-I448.

Pfeffer, R. I., A. A. Afifi., and J. M. Chance. 1987. "Prevalence of Alzheimer's Disease in a Retirement Community." American Journal of Epidemiology I25:420-435.

Pichot, Pierre. 1994. "Nosological Models in Psychiatry." British Journal of Psychiatry 164:232240.

Prince, M., D. Acosta, H. Chiu, M. Scazufca, and M. Varghese, Io/66 Dementia Research Group. 2003. "Dementia Diagnosis in Developing Countries: A Cross-Cultural Validation Study." Lancet 36I (936I): 909-9I7.

Rockwood, K., J. Graham, and S. Fay, for the ACADIE Investigators. 2002. "Goal Setting and Attainment in Alzheimer's Disease Patients Treated with Donepezil." Journal of Neurological and Neurosurgical Psychiatry 73:500-507.

Rockwood, K., I. Parhad, V. Hachinksi, T. Erkinjuntti, B. Rewcastle, A. Kertesz, M. R. Eastwood, and S. Phillips. 1994. "Diagnosis of Vascular Dementia: Consortium of Canadian Centres for Clinical Cognitive Research Consensus Statement.” Canadian Journal of Neurological Sciences 2I:358-364.

Rockwood, K., C. Wentzel, V. Hachinski, D. B. Hogan, C. MacKnight, and I. McDowell. 2000. "Prevalence and Outcomes of Vascular Cognitive Impairment. Vascular Cognitive Impairment Investigators of the Canadian Study of Health and Aging." Neurology 54 (2): 447-45I.

Román, G. C., T. K. Tatemichi, T. Erkinjuntii, J. L. Cummings, J. C. Masdeu, J. H. Garcia, L. Amaducci, J.-M. Orgogozo, A. Brun, A. Hofman, D. M. Moody, M. D. O’Brien, T. Yamaguchi, J. Grafman, B. P. Drayer, D. A. Bennett, M. Fisher, J. Ogata, E. Kokmen, F. Bermejo, P. A. Wolf, P. B. Gorelick, K. L. Bick, A. K. Pajeau, M. A. Bell, C. DeCarli, A. Culebras, A. D. Korczyn, J. Bogousslavsky, A. Hartmann, and K. Scheinberg. 1993. "Vascular Dementia: Diagnostic Criteria for Research Studies." Neurology 43:250-26o.

Roth, M., F. A. Huppert, E. Tym, and C. Q. Mountjoy. 1988. CAMDEX: The Cambridge Examination for Mental Disorders of the Elderly. Cambridge, U.K.: Cambridge University Press.

Rybicki, B. A., C. C. Johnson, and J. M. Gorell. 1995. "Demographic Differences in Referral Rates to Neurologists of Patients with Suspected Parkinson's Disease: Implications for Case-Control Study Design." Neuroepidemiology I4:472-48I.

Sackett, David L. 1979. "Bias in Analytic Research.” Journal of Chronic Disease 32:5I-63. 
Shepherd, G. M. 1994. Neurobiology. 3rd ed. New York: Oxford University Press.

Tallis, Raymond. 1996. "A Dark Mirror: Reflecting on Dementia." Conference given during "The Lancet Conference 1996: The Challenge of the Dementias." Edinburgh, U.K., April 25-26.

Teng, E. L., and H. C. Chui. 1987. "The Modified Mini-Mental State (3MS) Examination." Journal of Clinical Psychiatry 48:314-318.

Tuokko, H., R. Frerichs, J. Graham, K. Rockwood, B. Kristjansson, J. Fisk, H. Bergman, A. Kozma, and I. McDowell. 2003. "Five Year Follow-Up of Cognitive Impairment with No Dementia." Archives of Neurology 60:577-582.

Wind, A. W., F. G. Schellevis, G. van Stavern, R.J.P.M. Scholten, C. Hooijer, C. Jonker, and J.T.M. van Eijk. 1995. "Determinants of the Judgement of General Practitioners on Dementia." International Journal of Geriatric Psychiatry 10:767-776.

World Health Organization. 1989. Classification and Diagnosis of Alzheimer's Disease: An International Perspective. Toronto: Hogrefe and Huber.

—. 1993. The ICD-Io Classification of Mental and Behavioural Disorders: Diagnostic Criteria for Research. Geneva: World Health Organization.

Young, Allan. 1982. "The Anthropologies of Illness and Sickness." Annual Review of Anthropology II:257-264. 